\title{
Proposing a New Route to Solve Marine Debris Pollution Issues: Low-Temperature Eco-friendly Pulverization System by Utilizing LNG Cold Energy
}

\section{Dong-Ha Lee}

Department of Naval Architecture and Ocean Engineering, Pusan National University

\section{Sungkyun Park}

Department of Physics, Pusan National University

\section{Hee-Tae Kim}

Department of Naval Architecture and Ocean Engineering, Pusan National University

\section{Jeong-Dae Kim}

Department of Naval Architecture and Ocean Engineering, Pusan National University

\section{Jeong-Hyeon Kim}

Hydrogen Ship Technology Center, Pusan National University

\section{Seul-Kee Kim}

Hydrogen Ship Technology Center, Pusan National University

\section{Jung-Kwan Seo}

Department of Naval Architecture and Ocean Engineering, Pusan National University

\section{Pung-Keun Song}

Department of Materials Science and Engineering

Jeong-Eun Oh

Department of Civil and Environmental Engineering

\section{BuHyun Youn}

Department of Biological Sciences

\section{Gyung-Min Choi}

Department of Mechanical Engineering

Dong-Ha Lim

Korea Institute of Industrial Technology

Jae-Myung Lee ( $\nabla$ jaemlee@pusan.ac.kr)

Department of Naval Architecture and Ocean Engineering, Pusan National University

\section{Research Article}

Keywords: Marine debris, Eco-friendly low-temperature pulverizing system, LNG cold energy 
Posted Date: September 22nd, 2021

DOl: https://doi.org/10.21203/rs.3.rs-905766/v1

License: (c) (i) This work is licensed under a Creative Commons Attribution 4.0 International License. Read Full License 


\section{Abstract}

Developing an effective and efficient recycling process for marine debris (MD) is one of the most urgent issues to maintain Earth's sustainability. However, the restricted circumstances for collecting and separating MD in the ocean limit proper MD recycling. Here, we proposed a complete eco-friendly lowtemperature MD pulverizing system that utilizes excessive liquefied natural gas (LNG) cold energy (LCE) in an LNG propulsion ship to improve the efficiency and effectiveness of MD recycling. The prototype design of the low-temperature pulverization (LTP) system showed that consumable refrigerant (liquid nitrogen) up to $2831 \mathrm{~kg}$ per hour could be substituted. Furthermore, we estimated the additional refrigerant needed for desired MD disposal depending on the ship speed to determine the optimal energy requirement. In addition, LTP systems utilizing LCE can significantly improve the storage capacity by pulverizing bulky MD. To determine the feasibility of LTP for MD recycling, four types of plastics obtained from actual MD from a coastal area in Busan, Korea were classified and tested.

\section{Introduction}

Since the 1970s, marine debris (MD) has increased due to rapid industrialization ${ }^{1,2}$. MD can take a severe toll on biological ${ }^{3-6}$, economic ${ }^{7,8}$, and aesthetic (tourism) ${ }^{9,10}$ factors. Plastic production, which surged with industrialization in the 1950s, exceeded the cumulative production of 8.3 billion tons in 2017. According to Geyer et al., $59 \%$ of plastics are left unattended without being recycled or incinerated ${ }^{11}$. These plastics flow naturally into the ocean from land ${ }^{12,13}$. According to Eriksen et al., there are about 85 to 150 million tons of marine plastic debris (MPD) divided into 5 trillion pieces in the world's oceans, causing severe marine ecological issues ${ }^{14}$. Additionally, due to the COVID-19 pandemic, there are concerns that the increasing use of plastics, including personal protective equipment (PPE), is exacerbating marine pollution ${ }^{15,16}$. The lifetimes of MPD are relatively long and unpredictable. Therefore, they accumulate in the ocean for decades without decomposition ${ }^{17}$. In addition, secondary pollution of MPD owing to the marine environment such as corrosion, adhesion of shellfish, ingestion of marine organisms, leads them to be non-recyclable ${ }^{1,18}$. Currently, many non-profit environmental organizations are finding ways to resolve the issue of MPD distributed in the oceans, especially the Pacific Ocean ${ }^{19-23}$.

In general, cleaning ships equipped with facilities to dispose of floating and immersed wastes, collect and process MD. Figure 1 shows currently operating or developing MD collection vessels in the coastal and ocean areas. The ship in Fig. 1(a) is equipped with a system to gather plastic and trash at domestic and international locations by targeting local and land-based coastline issues. According to road transportation regulations, the ship in Fig. 1(b) can retrieve, compress, and pack waste. Furthermore, Fig. 1(c) shows a ship that can handle MD on board with an eco-friendly cleaning system that uses renewable energy. This vessel can gasify plastic and use it as fuel. Lastly, Fig. 1(d) shows a ship that collects floating MD in the Great Pacific Garbage Patch (GPGP) and picks up plastic and ghost nets with the support of a U-shaped arm. However, these ships are limited in terms of their operating radius and 
time because of the limited size of cargo capable of storing MD. Therefore, increasing the size of the MD cargo hold is a critical parameter that should be considered for better MD recycling.

Unfortunately, most collected MD is incinerated and disposed of in landfills, which causes not only severe environmental pollution ${ }^{24-27}$ but also additional time and costs. As ecological pollution intensifies, there have been more efforts to increase the efficiency of MPD recycling. According to the Northwest Pacific Action Plan (NOWPAP), current plastic recycling technologies can be classified into three categories: material recycling (or mechanical recycling), chemical recycling (or feedstock recycling), and thermal recycling (or energy recovery) ${ }^{28}$. Each methodology depends on the plastic's properties and potential usages of recycled plastics. Notably, all approaches have common issues in terms of pulverizing bulky MPD as a preprocessing step to enhance its portability and readiness for another use ${ }^{29,30}$. However, because of the low melting point of plastic (e.g., thermoplastics (TP)), it is difficult to pulverize plastics into smaller particle sizes. As an alternative, a low-temperature pulverization (LTP) process was proposed to improve pulverizing efficiency ${ }^{31-34}$. Furthermore, there was an attempt to construct a cooling system by utilizing the cold heat from a liquid gas storage tank such as liquefied natural gas (LNG) ${ }^{35-38}$.

Additionally, tightened ship emissions legislations have been increasing the demand for LNG propulsion ships. Marine emission legislations (e.g., Tier III requirements of the revised MARPOL Annex VI mandate) have required the reduction of NOx emissions by $20 \%$ (by 2020) and $50 \%$ (by 2050). Meanwhile, LNG in a cryogenic state uses an eco-friendly fuel in the transportation industry and onshore energy resources. Accordingly, many nations are making great efforts to demonstrate LNG-fueled propulsion systems ${ }^{39}$ since LNG can reduce the energy efficiency design index by $20 \% 40-42$.

According to Tian et al., given the dual-fuel engine ship, about $860 \mathrm{~kJ} / \mathrm{kg}$ of cold heat is wasted when LNG is vaporized and overheated ${ }^{43}$. Therefore, it is advantageous to improve and/or develop a system to maximize the usage of excessive LCE. The utilization of excessive LCE such as power generation, storage/transportation, desalination can be seen in many studies ${ }^{35}$. For example, in an LNG carrier (LNGC), boil-off gas (BOG) is generated by heat ingress in the LNG cargo containment system (CCS) ${ }^{44}$. Since BOG can increase the pressure of LNG CCS, it has to go through a reliquefication process, thus limiting LCE utilization offshore. Therefore, cryogenic power generation systems through the Organic Rankine cycle (ORC) and Brayton cycle are primarily applied ${ }^{45,46}$. However, the cold heat generated by LNG propulsion ships is less than that of LNGC and has rarely been used.

This study proposes a conceptual design that combines the MD disposal system and the residual cold energy utilization of an LNG-powered ship to build an eco-friendly and cost-effective LTP system. The amount of additional refrigerant used for freezing MD when the LCE system is operational is also quantified and evaluated in the prototypical ship for collecting MD. Further, LTP on MPD samples collected from a coastal shoreline of Busan, Korea was tested to show the feasibility of the proposed LTP system. As a result, this study shows that 1) LTP systems can be used to treat MD by processing MD into finer particles to improve the ship storage's capacity, and 2) building LCE-based LTP systems in LNG- 
fueled propulsion ships can provide an alternative route to improve MD recycling and upcycling to ensure Earth's sustainability.

\section{System Description}

Pulverization is an essential process for recycling marine waste. It turns processed plastics into different products in a single form, allowing for consistency in subsequent processes. Furthermore, this pretreatment process can be more economical and efficient if the energy required to collect and preprocess $M D$ is from surplus resources. For example, refrigeration using LCE can reduce initial investment and maintenance costs due to the simplification of facilities. In addition, using the existing refrigerant circulation system for the condensation-expansion process when using surplus LCE does not require additional equipment. Figure 2 shows the layout of the main facilities of an MD collection and cleaning ship equipped with an LTP facility. The facility is divided into two parts. The first is the propulsion part containing the LNG fuel tank. According to the eco-friendly trend in shipbuilding, MD collection and cleaning vessels are using LNG as fuel. LNG in the cryogenic state causes phase changes in the fuel gas supply system (FGSS), resulting in heat exchange. The gas is then combusted to generate the energy needed for power. Propulsion can also be carried out through the direct internal combustion of LNG, but in ships such as ferries, electric propulsion is also applied using an LNG power generator 47,48 . The second is the MD disposal part. In floating MD, collection through a conveyor is effective and can operate at a constant rate to bring the debris from the ocean directly to the storage cargo hold ${ }^{49}$. Furthermore, magnetic separators and dechlorination facilities are included. A detailed description of the pulverization process will be provided later (see Fig. 6).

Figure 3 shows a detailed schematic diagram of the system used to freeze MD for LTP. LNG lowers the temperature of ethylene glycol water (EGW) in the heat exchanger of the FGSS ${ }^{50}$. Ethylene glycol is typically used as a heat transfer medium owing to its low freezing point, which suits the low-temperature condition of the LNG stream ${ }^{35}$. Therefore, cold air with the circulating EGW decreases the temperature of MD via contact (i.e., air-blast method). As a result, MD is frozen to a brittle temperature. Furthermore, this LTP system (upper-right side of Fig. 3) supplies continuous cold energy without a heat exchanger.

To evaluate its potential cooling capacity and feasibility, we constructed a prototypical LNG propulsion cleaning ship with proper parameters. The ship has a cargo capacity of $1,300 \mathrm{~m}^{3}$ for loading MD and is equipped with an LTP facility capable of handling 20 tons of MD per day. The LTP facility operates in two units for cleaning efficiency, considering an eight-hour workload per day. Table 1 lists the specifications of the prototypical cleaning ship. Based on the ship's specification, the heat transfer rate for freezing MD is calculated as follows: 
Table 1

Principal particulars of prototypical cleaning vessel

\begin{tabular}{|lll|}
\hline Particulars & Specification & Unit \\
\hline Engine type & Himsen 5H22CDFP & - \\
\hline Engine rated power & 2,200 & $\mathrm{~kW}$ \\
\hline LNG Fuel Tank & $250 \times 2$ & $\mathrm{~m}^{3}$ \\
\hline LNG Pressure & 5 & bar \\
\hline Design Maximum Speed & 11.5 & $\mathrm{knots}$ \\
\hline Cruising Distance & 2,200 & $\mathrm{NM}$ \\
\hline Cargo Volume & 1,300 & $\mathrm{~m}^{3}$ \\
\hline Work Capacity & 20 & Ton/day \\
\hline
\end{tabular}

$$
\dot{Q}_{M D}=\dot{m}_{L N G}\left(h_{\text {out }}-h_{\text {in }}\right)
$$

1

where $Q_{M D}$ represents the heat transfer rate in the freezing chamber, and $h_{\text {out }}$ and $h_{\text {in }}$ represent specific enthalpy at the outlet and inlet of the heat exchanger. In this calculation, the temperature of the LNG at the outlet was fixed at $268 \mathrm{~K}$, and the system assumed adiabatic behavior ${ }^{51}$. Table 2 lists the embrittlement temperature and the specific heat of the test plastics ${ }^{52-56}$. The target temperature for pulverization was assumed to be the ductile-brittle transition temperature (DBTT). DBTT studies on many plastics have been performed. In this study, all plastics were assumed to be polyethylene to calculate the maximum refrigerant needed to reach DBTT. Additionally, to compare the efficiency of cooling systems, refrigerant consumption was calculated for liquid nitrogen $\left(\mathrm{LN}_{2}\right)$. Eq. (2) shows the relationship in the amount of refrigerant used for the LTP of plastics ${ }^{57}$;

Table 2

Properties of plastics applied to freezing and pulverizing

\begin{tabular}{|llll|}
\hline Polymer & DBTT $\left({ }^{\circ} \mathrm{C}\right)$ & Specific heat $(\mathrm{J} / \mathrm{kgK})$ & Reference \\
\hline PA & 230 & 1700 & 52 \\
\hline PE & 230 & 1900 & 53 \\
\hline PET & 240 & 1200 & 54 \\
\hline PP & 250 & 1700 & 55 \\
\hline PVC & 270 & 1250 & 56 \\
\hline
\end{tabular}




$$
M C_{p M}\left(T_{i}-T_{s}\right)=G C_{p R}\left(T_{g O}-77.4\right)
$$

2

where $M$ is the flow rate of $M D\left(\mathrm{~kg} / \mathrm{h} \mathrm{m}^{2}\right), C_{P M}$ is the specific heat of $M D(\mathrm{~J} / \mathrm{kg} \mathrm{K}), T_{i}$ is the inlet temperature of $M D(K), T_{s}$ is the temperature of $M D$ at the end of the pre-cooling section $(K), G$ is the flow of refrigerant $\left(\mathrm{kg} / \mathrm{h} \mathrm{m}^{2}\right), \mathrm{C}_{\mathrm{pR}}$ is the specific heat of refrigerant $(\mathrm{J} / \mathrm{kg} \mathrm{K})$, and $\mathrm{T}_{\mathrm{gO}}$ is the outlet temperature of refrigerant $(K)$.

If the flow rate of $M D$ is expressed as the ratio of refrigerant flow, the amount of refrigerant needed to pulverize MD (i.e., $M / G$ ) can be calculated as follows;

$$
\frac{M}{G}=C_{p R}\left(T_{g O}-77.4\right) / C_{p M}\left(T_{i}-T_{s}\right)
$$

3

.It is worth noting that the available LCE for MD collection and cleaning is limited when the cleaning ship moves at a relatively low speed because of the less excessive LCE. Therefore, it is necessary to determine the MD freezing capacity depending on the speed of a ship, which can be calculated from the fuel consumption. Assuming the prototypical ship is equipped with a Himsen engine (Hyundai Heavy Industry, $\mathrm{HHI}$ ) and its specific gas consumption (SGC) based on maximum continuous rating (MCR) is 163.42 $\mathrm{g} / \mathrm{kWh}$, the amount of freezing capacity using LCE per hour $\left(W_{L C E}\right)$ according to the output of the ship $\left(P_{E}\right)$ is as follows;

$$
W_{L C E}=\frac{h_{o u t}-h_{\text {in }}}{C_{p M}\left(T_{i}-T_{s}\right)} \times S G C \times P_{E}
$$

4Furthermore, $P_{E}$ is proportional to $v^{3}$, where $v$ is the ship's speed ${ }^{58}$. Figure 4 shows the calculated $W_{L C E}$ depending on the ship's speed, $v$. It is worth noting that the estimated $W_{L C E}$ based on MCR, which is less than $10 \%$ (around 5 knots in this study), is inaccurate. Therefore, the minimum speed for collecting marine waste is assumed to be 5 knots. In addition, MD collection and LTP are independent processes, suggesting that two processes can be done simultaneously (i.e., independently) when a ship is in operation. However, much fuel is consumed when a ship sails at a high output after MD collection. For example, $1,858 \mathrm{~kg}$ of MD can be frozen per hour at the speed of $10 \mathrm{knots} / 2831 \mathrm{~kg}$ at the design speed. Therefore, more effective LTP can be done at a high speed.

In general, MD collection ships need to stay in the ocean for a long time compared to merchant and passenger ships. Therefore, the targeted collection area and LTP throughput should be designed by adjusting the size of the LNG fuel tank. Considering that optimal MD collection is operated at speeds of 5 knots or less, it is possible to freeze up to $250 \mathrm{~kg}$ of MD per hour without any additional energy. Therefore, if an additional refrigerant (e.g., $\mathrm{LN}_{2}$ ) is used, the extra $\mathrm{MD}$ can be frozen and pulverized. The additional amount of liquid nitrogen $\left(W_{L N 2}\right)$, needed for overflow MD freezing and pulverizing can be derived as follows from Equations (3) and (4): 


$$
W_{L N 2}=W_{L C E} \times \frac{M}{G}+M F C
$$

5

where MFC means the minimum freezing capacity according to the MCR. The correlation between $W_{L N 2}$ and $W_{L C E}$ for various MCR is shown in Fig. 5. The slop $(\mathrm{M} / \mathrm{G})$ is constant regardless of the percentage of MCR expected. Suppose the ship is not in operation (i.e., $M C R=0 \%$ ). Then, MD should be frozen through $L N_{2}$ only. However, if an MD collection ship increases the power output, the $L C E$ replaces $L N_{2}$. For example, it is possible to freeze $246 \mathrm{~kg}$ ( $514 \mathrm{~kg}$ ) of MD per hour at an output of 10\% (20\%) MCR without additional refrigerant. The corresponding ship's speed for each output is 5.34 knots for $10 \%$ MCR and 6.73 knots for $20 \%$ MCR.

Figure 6 shows the detailed LTP process of MD using LCE. The collected waste is classified into MD and marine organisms. Since marine organisms such as echinoderms and seaweeds inhabit the seabed, they should be separated. Further, among the classified MD, fiber-type waste, such as dumped fishing nets or rope, are sorted out because entanglement and overload can be induced in the shredding and grinding process ${ }^{59}$. In addition, floating MD may contain metals and/or other high-density materials. In the case of wasted metals, the magnetic separator is used to filter out any pieces. At the same time, high-density materials should be separated through specific gravity sorting prior to the cutting process. The remaining MD is primarily crushed by a shredding machine. The shredding machine has the advantage of a high grinding capacity. However, the ground particle size is relatively large at $\sim 50 \mathrm{~mm}{ }^{60}$. Therefore, improving the LTP efficiency requires further processing to a particle size of $20 \mathrm{~mm}$ or less. To do this, the particles are stored in a low-temperature freezer (e.g., $233 \mathrm{~K}$ ) for a while prior to the LTP process. To lower the refrigerant temperature in the freezer, the LCE, which is waste energy, is supplied to the FGSS.

Some collected plastic MD contains chlorine. For example, polyvinyl chloride (PVC) is a TP amorphous with a high molecular compound used in various places due to its low price, rigidity, and high immutability ${ }^{61}$. However, since PVC contains chlorine, many toxic substances such as dioxins and furans may be generated during incineration and thermal decomposition. Therefore, a separate dechlorination process is required ${ }^{62}$. In addition, electrochemical treatment is essential due to the high salinity of $\mathrm{MD}$ and wastewater generated from the pulverizing process. $\mathrm{IrO}_{2}$ electrodes have been widely used for wastewater desalination. However, boron-doped diamond (BDD) electrodes were developed to generate strong oxidizing agents such as $\mathrm{OH}$ - Strong oxidants can react with $\mathrm{Cl}$ in plastics (or $\mathrm{Cl}$ - of waste seawater) to produce additional oxidants such as hypochlorous acid (HCLO) and perchlorate $\left(\mathrm{CLO}_{4}{ }^{-}\right)$, which can remove chlorine. Figure 7 shows the schematics of drum-type capacitive dichlorination (CD) equipment with a ball mill reactor and the detailed chemical process related to dichlorination. Drum-type dechlorination facilities are designed to perform plastic dechlorination treatments at a $470 \mathrm{~K}$ or higher temperature with BDD electrodes.

\section{Marine Debris Pulverization}


LTP, which is a pre-treatment process for waste recycling, is known to improve storage efficiency. Figure 8 shows the typical bulk MD with a small density $\left(106 \mathrm{~kg} / \mathrm{m}^{3}\right)$ and a large volume. Therefore, collection bulk MD without processing prevents mass collection. Although collecting floating MD using ocean currents, not loading onto the cargo of a cleaning ship, has been proposed to save on storage space, the usages of this technique are still limited to certain regions and specific environments (Jambeck and Johnsen, 2015; Sterenborf et al., 2019). However, pulverizing MD into particles smaller than $5 \mathrm{~mm}$ increases the density to $420-770 \mathrm{~kg} / \mathrm{m}^{3}$, increasing the loading efficiency up to seven times.

Furthermore, the additional compression process increases the packing density by more than 10 times. Therefore, an energy-efficient pulverizing (e.g., LTP process) and compression process is essential to enhance a ship's cleaning capacity and long-term operation.

A practical test to determine the feasibility of the LTP process of TP-MPD was performed. The MPD used for the pulverization test was collected within the range of $4 \mathrm{~km}$ off the coast of Busan, Korea as shown in Fig. 9(a). A cleaning ship operated by the Korean government collected floating MD (Fig. 9(b)) and seabed MD (Fig. 9(c)). As mentioned in Sect. 2, MD collected by cleaning ships is currently stored in warehouses prior to moving to a landfill or incineration since recycling is inefficient due to contamination and chemical decomposition ${ }^{64}$. In particular, fishing nets and rope from fishing boats, as shown in Fig. 9 (c), are highly corroded and decomposed, so the recycling cost is very high. Furthermore, the processing procedure is very complicated.

Randomly collected floating MD from a conveyor method was primarily classified by manual labor into four materials: polyethylene terephthalate (PET), expanded polystyrene (EPS), polyamide (PA), and polypropylene (PP) (Fig. 10(a-d)). PET was acquired through land-based household waste, and EPS was chosen from buoys among the floating waste. PA and PP were obtained from abandoned nets and rope among those dumped from fishing boats. Furthermore, classified MD was confirmed through Fouriertransform infrared spectroscopy (FT-IR) analysis (Lee et al., 2020) that allowed a comparison with reference materials (Jung et al., 2018). In general, ultrasonic mill, jet mill, and ball mill are used to make fine particles ${ }^{65-67}$. However, it is advantageous to select a cutter mill or an impactor mill for large pulverizing volumes such as waste. Therefore, the impactor mill, which had two opposite blades at 24,000 RPM, was used to pulverize the material while circulating $\mathrm{LN}_{2}$ to maintain a low temperature. The temperature was set to $220 \mathrm{~K}$ followed by an hour of pre-cooling before pulverization. In addition, the temperature was monitored in real time to prevent the increase in temperature during pulverization.

A sieve test was conducted to analyze the pulverized particle size distribution. The sieve sizes were 0.25 , $0.5,1,2$, and $4 \mathrm{~mm}$, respectively. The standard sieve had a squared mesh so that particles could pass through up to $\sqrt{2}$ times the mesh size for ground particles with irregular shapes as shown in Fig. 11(a). Figure 11(b) shows the sieve test results.

In the case of PET particles pulverized at room temperature (PET-RT), about $76 \%$ of the particles failed to pass the largest sieve. In addition, melting and clumping around the edges were observed because of the high temperature of the pulverizing environment (Fig. 11(c)). PET particles pulverized at low temperature 
(PET-LT) around $223 \mathrm{~K}$ showed no noticeable edge melting and clumping. In particular, $82 \%$ of the particles formed a particle size of less than $4 \mathrm{~mm}$. Since EPS is produced by foaming polystyrene, it comprises a cell structure. The bond was broken between cells when it was ground even at room temperature, while the cell structure of EPS was crushed under low temperature (Fig. 11(c)). It is worth noting that rising temperatures in the pulverizing process cause plastic to melt. Due to the generation of a significant amount of endocrine-disrupting chemicals in this process, this should be resolved in the process of recycling ${ }^{68}$. In addition, existing crushing processes produce particles randomly distributed particle sizes, which degrades recycling quality. Uniform fine particles through LTP are eco-friendly and enable high-quality recycling.

\section{Summary}

This study demonstrated a prototypical concept for an eco-friendly low-temperature MD pulverizing system that utilizes the cold energy from an LNG-powered cleaning ship. Typical cleaning ships used these days have a limited loading efficiency due to the low bulk density and larger volume of MD. As such, they mainly operate in coastal areas. However, the proposed concept can collect MD in the oceanic region because the MD loading capacity increases by more than 10 times through LTP and compression processes. Furthermore, the energy source for the LTP is mostly from excessive cold energy from LNG propulsion ships, which is essential for the upcoming low- $\mathrm{CO}_{2}$ emission requirement. It is also expected to dramatically reduce refrigerants used in LTP processes. By utilizing LCE at the ship's designed speed (e.g., 11.5 knots in this study), it is expected that more than 2 tons of MD per hour can be frozen, and 200 $\mathrm{kg}$ of MD can be processed per hour even during collection at $\sim 5$ knots. In addition, the savings according to the ship's output were calculated in the cooling of MD using $\mathrm{LN}_{2}$. With an output of $20 \%$ MCR, more than $514 \mathrm{~kg}$ of MD can be processed per hour without using additional refrigerants. These results suggest that up to $253 \mathrm{~kg}$ of $\mathrm{LN}_{2}$ per hour can be saved during ship operation. To show the feasibility of the conceptual design, we estimated the amount of energy needed for a proper cleaning capacity on various ship speeds. The outcomes are promising even though there is room for improvement. For example, the energy conversion efficiency and optimal system configurations in designing an LNG-powered cleaning ship can be improved with technological development. To evaluate the low-temperature process for adequate MD pulverization, residual particle size analysis was conducted. The results showed that LTP is advantageous for fine particle production and is eco-friendly by preventing melting. The proposed idea can resolve critical environmental issues in the ocean, but it can be generalized to ensure the utilization of any excess energy in modern industries.

\section{Declarations}

\section{Acknowledgements}

This work was supported by the R\&D Platform Establishment of Eco-Friendly Hydrogen Propulsion Ship Program (No. 20006644 and 20006632), funded by the Ministry of Trade, Industry \& Energy (MOTIE, 
Korea). Authors also thank Korea Marine Environment Management Corporation(KOEM) for supporting the MD collection used in this study.

\section{References}

1. Thevenon, F., Carroll, C. \& Sousa, J. Plastic debris in the ocean: the characterization of marine plastics and their environmental impacts, situation analysis report.Gland, Switzerland: IUCN52, (2015).

2. Ivar do Sul, J. A. \& Costa, M. F. Marine debris review for Latin America and the Wider Caribbean Region: From the 1970s until now, and where do we go from here? Mar. Pollut. Bull, 54, 1087-1104 (2007).

3. Laist, D. Bio Effects of Lost and Discarded Plastics on Marine Biota (Good Opening Line). Mar. Pollut. Bull, 18, 319-326 (1987).

4. Choy, C. A. et al. The vertical distribution and biological transport of marine microplastics across the epipelagic and mesopelagic water column. Sci. Rep, 9, 1-9 (2019).

5. Vethaak, A. D. \& Leslie, H. A. Plastic Debris is a Human Health Issue. Environ. Sci. Technol, 50, 68256826 (2016).

6. Gall, S. C. \& Thompson, R. C. The impact of debris on marine life. Mar. Pollut. Bull, 92, 170-179 (2015).

7. Mcllgorm, A., Campbell, H. F. \& Rule, M. J. The economic cost and control of marine debris damage in the Asia-Pacific region. Ocean Coast. Manag, 54, 643-651 (2011).

8. Beaumont, N. J. et al. Global ecological, social and economic impacts of marine plastic. Mar. Pollut. Bull, 142, 189-195 (2019).

9. Zhao, S., Zhu, L. \& Li, D. Characterization of small plastic debris on tourism beaches around the South China Sea. Reg. Stud. Mar. Sci, 1, 55-62 (2015).

10. Jang, Y. C., Hong, S., Lee, J., Lee, M. J. \& Shim, W. J. Estimation of lost tourism revenue in Geoje Island from the 2011 marine debris pollution event in South Korea. Mar. Pollut. Bull, 81, 49-54 (2014).

11. Geyer, R., Jambeck, J. R. \& Law, K. L. Production, use, and fate of all plastics ever made. Sci. Adv, 3, 25-29 (2017).

12. Jambeck, J. R. et al. Plastic waste inputs from land into the ocean. Science (80-), $347,768-771$ (2015).

13. Seo, S. \& Park, Y. G. Destination of floating plastic debris released from ten major rivers around the Korean Peninsula. Environ. Int, 138, 105655 (2020).

14. Eriksen, M. et al. Plastic Pollution in the World's Oceans: More than 5 Trillion Plastic Pieces Weighing over 250,000 Tons Afloat at Sea. PLoS One, 9, 1-15 (2014).

15. Patrício Silva, A. L. et al. Increased plastic pollution due to COVID-19 pandemic: Challenges and recommendations. Chem. Eng. J, 405, 126683 (2021). 
16. Canning-Clode, J., Sepúlveda, P., Almeida, S., Monteiro, J. \& Will COVID-19 Containment and Treatment Measures Drive Shifts in Marine Litter Pollution? Front. Mar. Sci, 7, 2018-2021 (2020).

17. Quayle, D. V. Plastics in the Marine Environment: Problems and Solutions. Chem. Ecol, 6, 69-78 (1992).

18. Kershaw, P., Katsuhiko, S., Lee, S. \& Woodring, D. Plastic Debris in the Ocean.UNEP Year B.(2011).

19. Lebreton, L. et al. Evidence that the Great Pacific Garbage Patch is rapidly accumulating plastic. Sci. Rep, 8, 1-15 (2018).

20. Holst, R. R. \& The Netherlands The 2018 agreement between the ocean Cleanup and the Netherlands. Int. J. Mar. Coast. Law, 34, 351-371 (2019).

21. Rojas, J. Plastic waste is exponentially filling our oceans, but where are the robots? IEEE Reg. 10 Humanit. Technol. Conf, (R10-HTC), 1-6 (2018).

22. Golden, D., Fitzimons, J., Doyle, T. \& Hayes, D. Zero-fuel open ocean-going tugs, and applications for the large scale collection of ocean plastics. Ocean. 2019 MTS/IEEE Seattle, Ocean.(2019).

23. Jung, R. T., Sung, H. G., Chun, T. B. \& Keel, S. I. Practical engineering approaches and infrastructure to address the problem of marine debris in Korea. Mar. Pollut. Bull, 60, 1523-1532 (2010).

24. Kazour, M. et al. Sources of microplastics pollution in the marine environment: Importance of wastewater treatment plant and coastal landfill. Mar. Pollut. Bull, 146, 608-618 (2019).

25. Fauziah, S. H. et al. Marine debris in Malaysia: A review on the pollution intensity and mitigating measures. Mar. Pollut. Bull, 167, 112258 (2021).

26. Yang, Z. et al. Is incineration the terminator of plastics and microplastics? J. Hazard. Mater, 401, 123429 (2021).

27. Williams-Wynn, M. D. \& Naidoo, P. A review of the treatment options for marine plastic waste in South Africa. Mar. Pollut. Bull, 161, 111785 (2020).

28. Nowpap Cearac.Recycling Plastic Marine Litter.36, (2007).

29. Hossain, M. S., Gabr, M. A. \& Asce, F. The effect of shredding and test apparatus size on compressibility and strength parameters of degraded municipal solid waste. Waste Manag, 29, 2417-2424 (2009).

30. Waleola Ayo, A., Olukunle, O. \& Adelabu, D. Development of a Waste Plastic Shredding Machine. Int. J. Waste Resour, 07, 2-5 (2017).

31. Adhikari, J., Das, A., Sinha, T., Saha, P. \& Kim, J. K. CHAPTER 1: Grinding of Waste Rubber. RSC Green Chem, 2019-Janua, 1-23 (2019).

32. Wang, P. \& Liu, S. Y. Recovery of waste rubber through pulverization at a low temperature of refrigeration by an air turbine. Proc. Inst. Mech. Eng. Part E J. Process Mech. 213, 135-138(1999).

33. Bilgili, E., Arastoopour, H. \& Bernstein, B. Pulverization of rubber granulates using the solid-state shear extrusion (SSSE) process: Part I. Process concepts and characteristics. Powder Technol, 115, 265-276 (2001). 
34. Jonna, S. \& Lyons, J. Processing and properties of cryogenically milled post-consumer mixed plastic waste. Polym. Test, 24, 428-434 (2005).

35. He, T., Chong, Z. R., Zheng, J., Ju, Y. \& Linga, P. LNG cold energy utilization: Prospects and challenges. Energy, 170, 557-568 (2019).

36. Shi, X., Agnew, B., Che, D. \& Gao, J. Performance enhancement of conventional combined cycle power plant by inlet air cooling, inter-cooling and LNG cold energy utilization. Appl. Therm. Eng, 30, 2003-2010 (2010).

37. Sun, W., Hu, P., Chen, Z. \& Jia, L. Performance of cryogenic thermoelectric generators in LNG cold energy utilization. Energy Convers. Manag, 46, 789-796 (2005).

38. Mehrpooya, M., Sharifzadeh, M. M. M. \& Rosen, M. A. Optimum design and exergy analysis of a novel cryogenic air separation process with LNG (liquefied natural gas) cold energy utilization. Energy, 90, 2047-2069 (2015).

39. Wei, Y. J., Duan, G., Tao, L., Chen, X. H. \& Fan, T. New energy vessel routing and optimization for marine debris collection under uncertain environment. J. Phys. Conf. Ser. 1903, (2021).

40. Briefs, S. et al. Emissions from marine engines versus IMO certification and requirements of tier 3 . Appl. Mech. Mater, 93, 161-167 (2013).

41. Herdzik, J. Emissions from marine engines versus IMO certification and requirements of tier 3. J. KONES, 18, 161-167 (2011).

42. Azzara, A. A., Rutherford, D. \& Wang, H. Feasibility of IMO Annex VI Tier III implementation using Selective Catalytic Reduction. Int. Counc. Clean Transp, 4, 1-9 (2014).

43. Tian, Z., Yue, Y., Gu, B., Gao, W. \& Zhang, Y. Thermo-economic analysis and optimization of a combined Organic Rankine Cycle (ORC) system with LNG cold energy and waste heat recovery of dual-fuel marine engine. Int. J. Energy Res, 44, 9974-9994 (2020).

44. Dobrota, Ä., Lalić, B. \& Komar, I. Problem of Boil - off in LNG Supply Chain. Trans. Marit. Sci, 2, 91100 (2013).

45. Mosaffa, A. H., Mokarram, N. H. \& Farshi, L. G. Thermo-economic analysis of combined different ORCs geothermal power plants and LNG cold energy. Geothermics, 65, 113-125 (2017).

46. Gómez, M. R., Garcia, R. F., Gómez, J. R. \& Carril, J. C. Thermodynamic analysis of a Brayton cycle and Rankine cycle arranged in series exploiting the cold exergy of LNG (liquefied natural gas). Energy, 66, 927-937 (2014).

47. Nuchturee, C., Li, T. \& Xia, H. Energy efficiency of integrated electric propulsion for ships - A review. Renewable and Sustainable Energy Reviews, 134, 110145 (2020).

48. Pestana, H. Future trends of electrical propulsion and implications to ship design.Marit. Technol. Eng.811-820(2014).

49. Chrissley, T., Yang, M., Maloy, C. \& Mason, A. Design of a Marine Debris Removal System. 2017 Syst. Inf. Eng. Des. Symp. SIEDS. 10-15(2017). 
50. Choi, J. \& Park, E. Y. Comparative study on fuel gas supply systems for LNG bunkering using carbon dioxide and glycol water.J. Mar. Sci. Eng.7, (2019).

51. Baldasso, E., Mondejar, M. E., Mazzoni, S., Romagnoli, A. \& Haglind, F. Potential of liquefied natural gas cold energy recovery on board ships. J. Clean. Prod, 271, 122519 (2020).

52. Huang, J. J., Keskkula, H. \& Paul, D. R. Comparison of the toughening behavior of nylon 6 versus an amorphous polyamide using various maleated elastomers. Polymer (Guildf), 47, 639-651 (2006).

53. Brown, N. \& Ward, I. M. The influence of morphology and molecular weight on ductile-brittle transitions in linear polyethylene. J. Mater. Sci, 18, 1405-1420 (1983).

54. Loyens, W. \& Groeninckx, G. Rubber toughened semicrystalline PET: Influence of the matrix properties and test temperature. Polymer (Guildf), 44, 123-136 (2002).

55. Tiwari, R. R. \& Paul, D. R. Polypropylene-elastomer (TPO) nanocomposites: 3. Ductile-brittle transition temperature. Polymer (Guildf), 53, 823-831 (2012).

56. Hassan, A. \& Haworth, B. Impact properties of acrylate rubber-modified PVC: Influence of temperature. J. Mater. Process. Technol, 172, 341-345 (2006).

57. Biddulph, M. W. Cryogenic embrittlement of rubber. Cons. \& Recy, 1, 169-178 (1977).

58. Kim, S. K., Lee, Y. S., Kong, G. Y., Kim, J. P. \& Jung, C. H. A Study on the Ship's Speed for Reducing the Fuel Oil Consumption in Actual Ships. J. Korean Soc. Mar. Environ. Saf, 18, 41-47 (2012).

59. Uddin, S., Rao, S. R., Mirnezami, M. \& Finch, J. A. Processing an ultramafic ore using fiber disintegration by acid attack. Int. J. Miner. Process, 102-103, 38-44 (2012).

60. Khodier, K., Feyerer, C., Möllnitz, S., Curtis, A. \& Sarc, R. Efficient derivation of significant results from mechanical processing experiments with mixed solid waste: Coarse-shredding of commercial waste. Waste Manag, 121, 164-174 (2021).

61. Sadat-Shojai, M. \& Bakhshandeh, G. R. Recycling of PVC wastes. Polym. Degrad. Stab, 96, 404-415 (2011).

62. Sun, R. et al. Suppressing effect of $\mathrm{CaCO} 3$ on the dioxins emission from poly(vinyl chloride) (PVC) incineration. Polym. Degrad. Stab, 79, 253-256 (2003).

63. Jambeck, J. R. \& Johnsen, K. Citizen-based litter and marine debris data collection and mapping. Comput. Sci. Eng, 17, 20-26 (2015).

64. Sung, H., Jung, R., Yu, J. \& Kang, C. Practical Approches To Marine Debris in Korean Sea Waters. 1st Jt. Korea/Japan Work. Mar. Environ. Eng. 73-86(2003).

65. Wang, H. et al. Surface grinding of carbon fiber-reinforced plastic composites using rotary ultrasonic machining: Effects of tool variables. Adv. Mech. Eng, 8, 1-14 (2016).

66. Palaniandy, S., Kadir, N. A. \& Jaafar, M. Value adding limestone to filler grade through an ultra-fine grinding process in jet mill for use in plastic industries. Miner. Eng, 22, 695-703 (2009).

67. Kameda, T., Ono, M., Grause, G., Mizoguchi, T. \& Yoshioka, T. Ball mill-assisted dechlorination of flexible and rigid poly (vinyl chloride) in $\mathrm{NaOH} / \mathrm{EG}$ solution. Ind. Eng. Chem. Res, 47, 8619-8624 (2008). 
68. Lomonaco, T. et al. Release of harmful volatile organic compounds (VOCs) from photo-degraded plastic debris: A neglected source of environmental pollution. J. Hazard. Mater, 394, 122596 (2020).

\section{Figures}
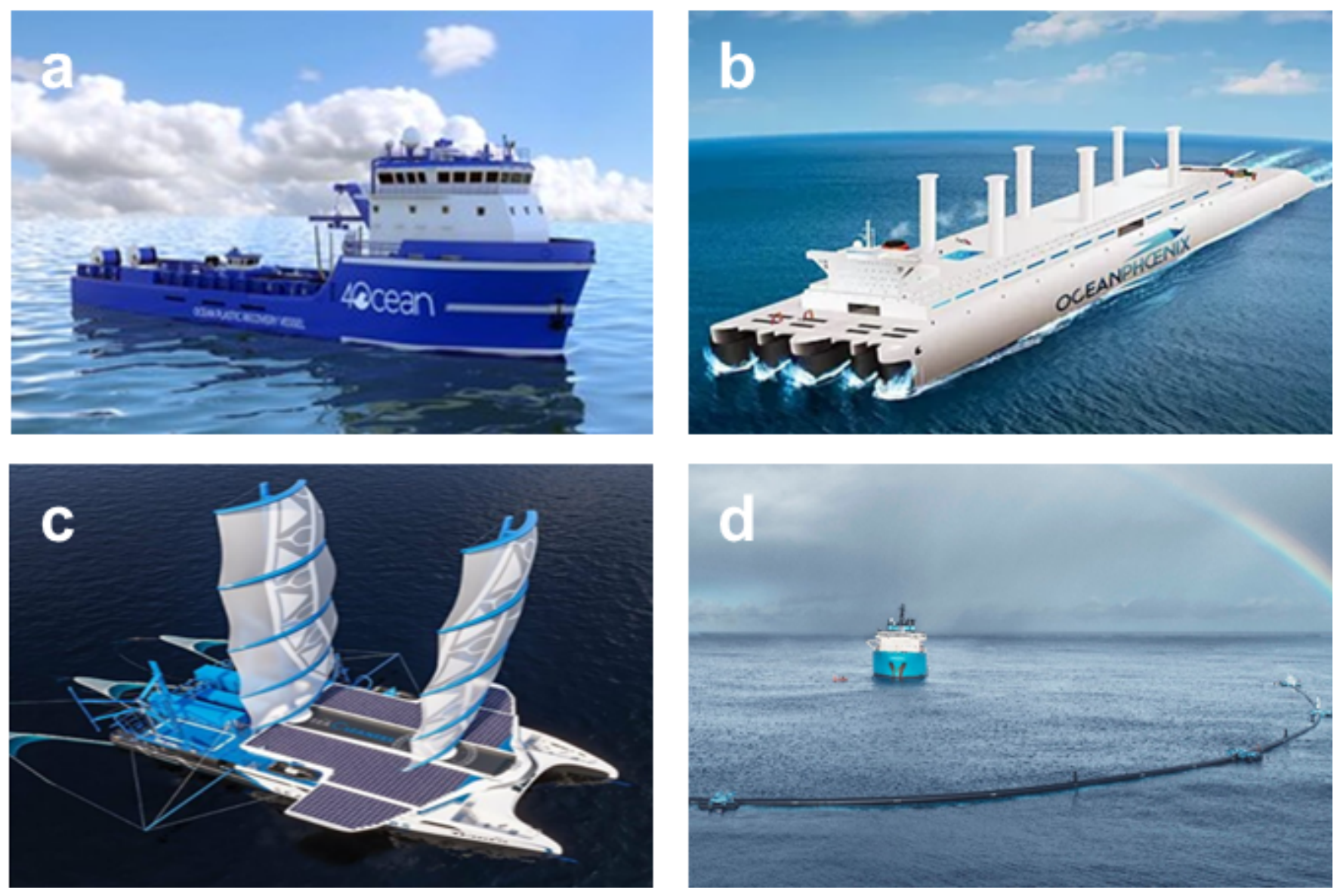

\section{Figure 1}

(a) 135-foot ocean plastic recovery vessel. This ship assists in gathering plastic and trash in domestic and international locations by targeting local and land-based coastline issues (Source:

https://www.oceansplasticleanup.com/, July 31st, 2021). (b) Ocean phoenix 360. This ship can retrieve, compress, and pack waste (Source: https://www.oceanphoenixproject.com/, July 31st, 2021). (c) Ecofriendly cleaning ship with solar and wind generation system. It has a plasma gasification facility to produce fuel for ships (Source: https://www.theseacleaners.org/, July 31st, 2021). (d) Ocean cleanup system. This system takes advantage of natural oceanic forces to catch and concentrate plastic (Source: https://theoceancleanup.com/, July 31st, 2021). 


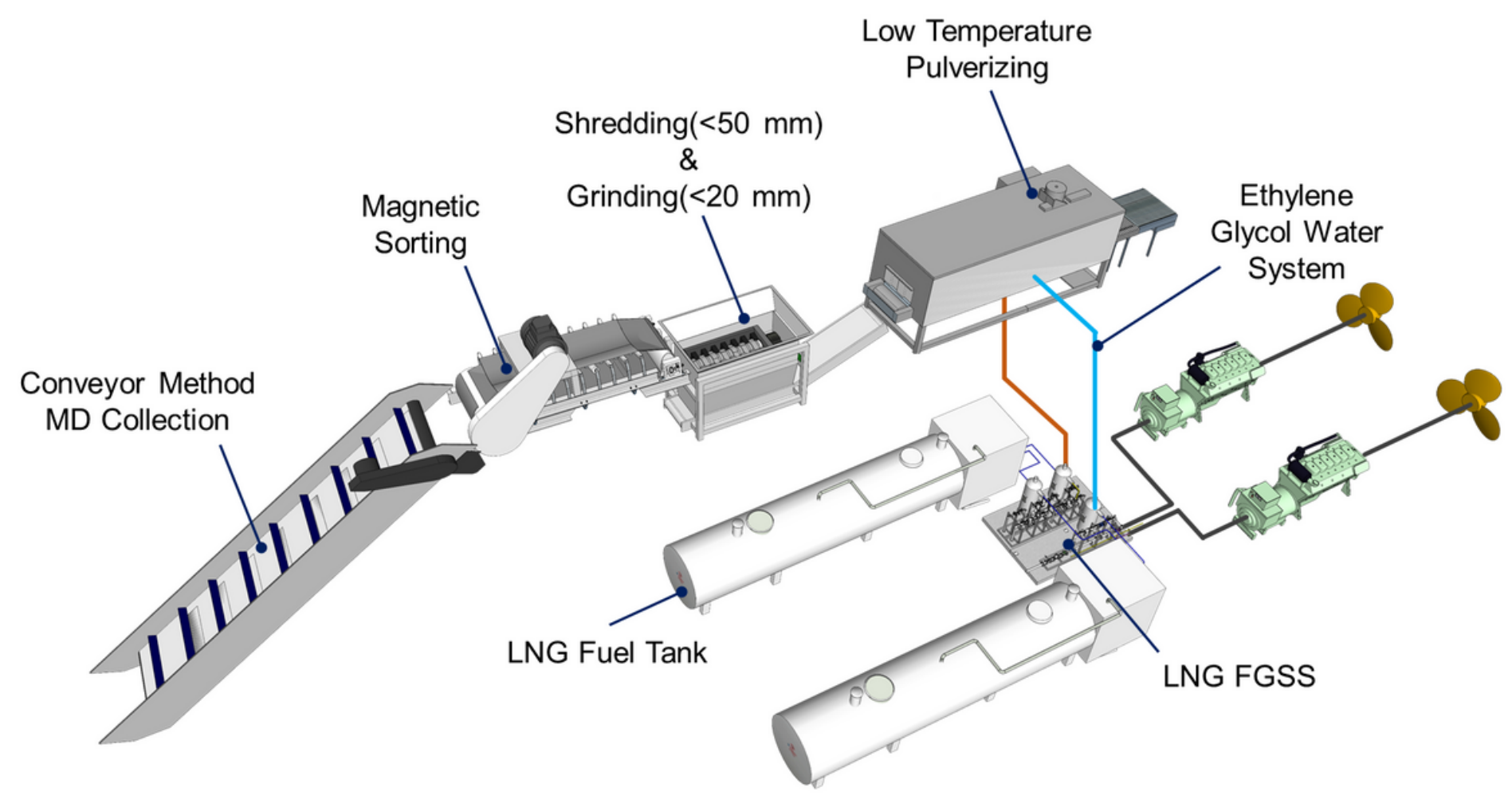

Figure 2

Layout for LNG-fueled propulsion system equipped with an LTP system utilizing LCE.

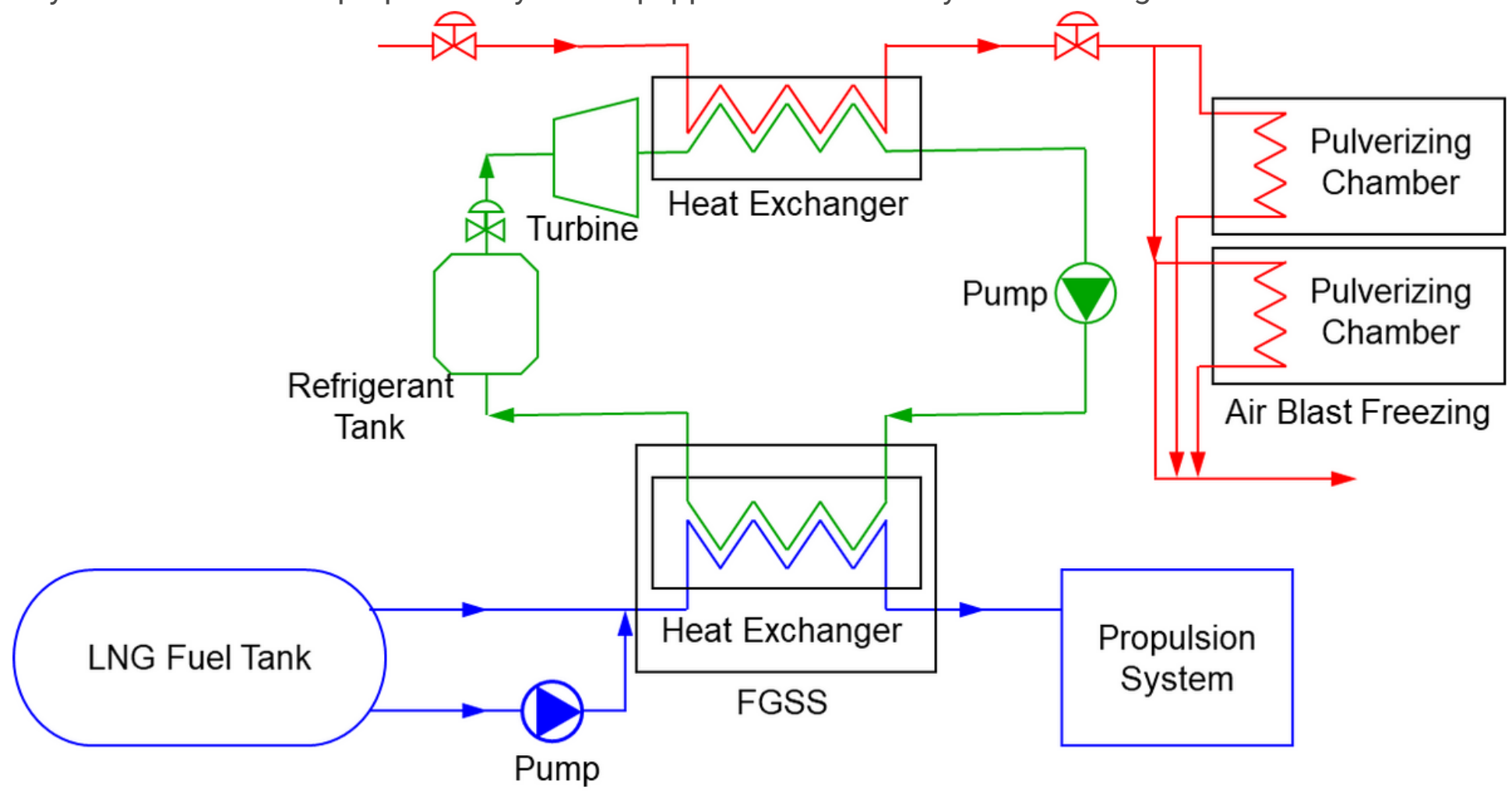

Figure 3 
Schematic diagram of LNG-fuelel propulsion system with LTP system. It contains the LNG propulsion part (blue line), EGW system (green line), and pulverizing chamber with an air-blast freezing system (red line).

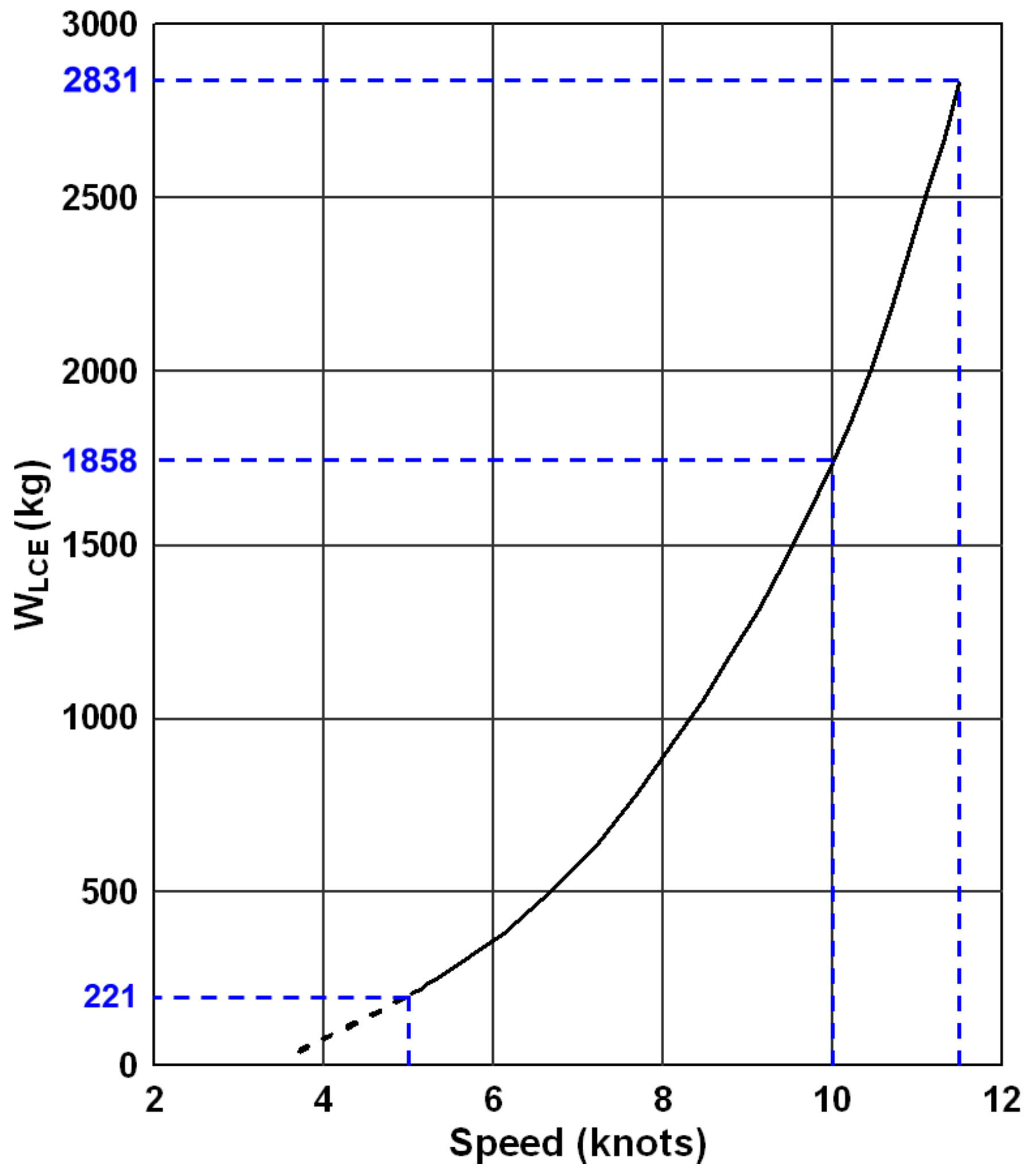

Figure 4

Maximum MD freezing capacity according to the ship's speed. 


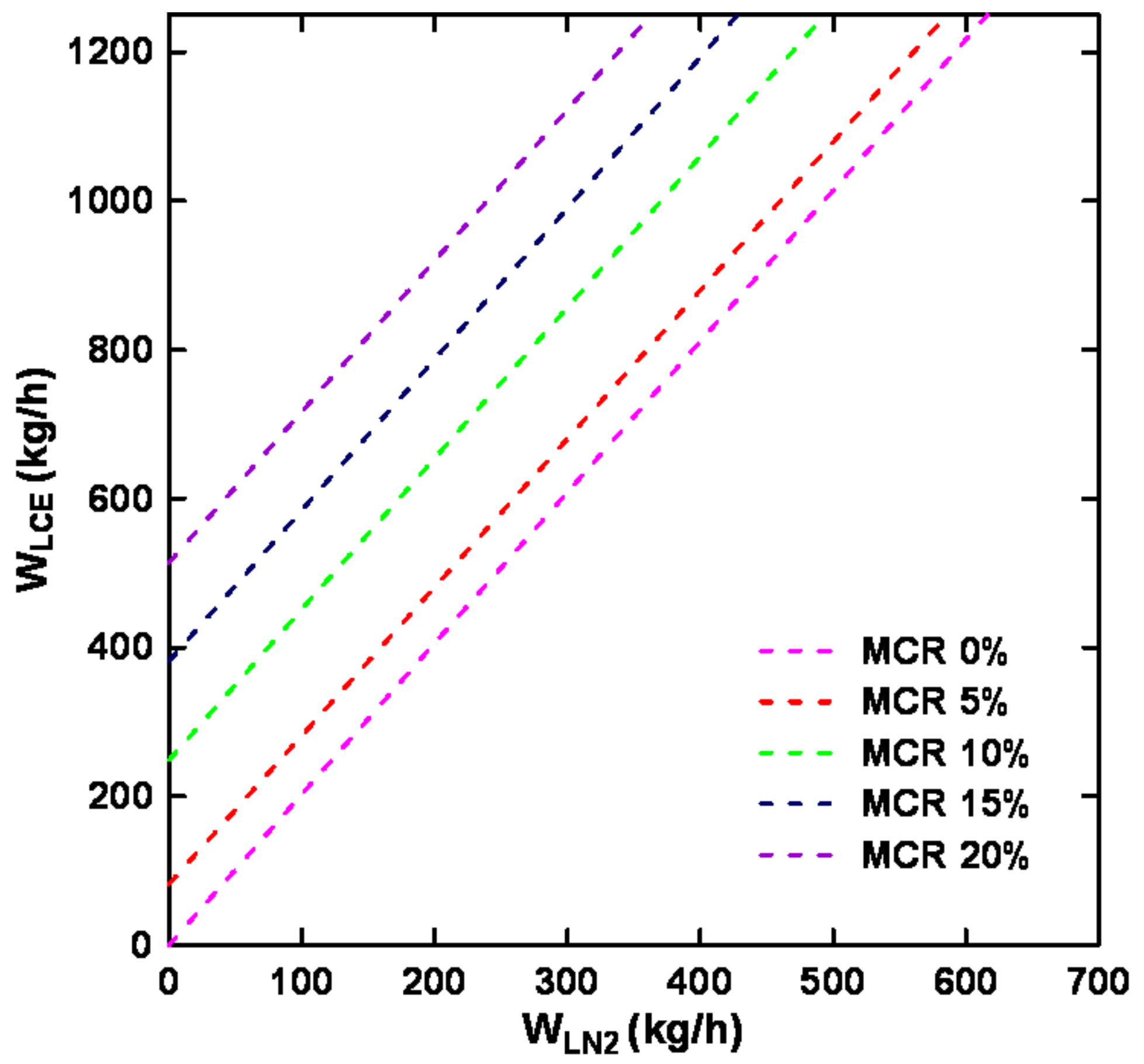

Figure 5

MD freezing capacity compared to liquid nitrogen consumption according to the ship's output. 


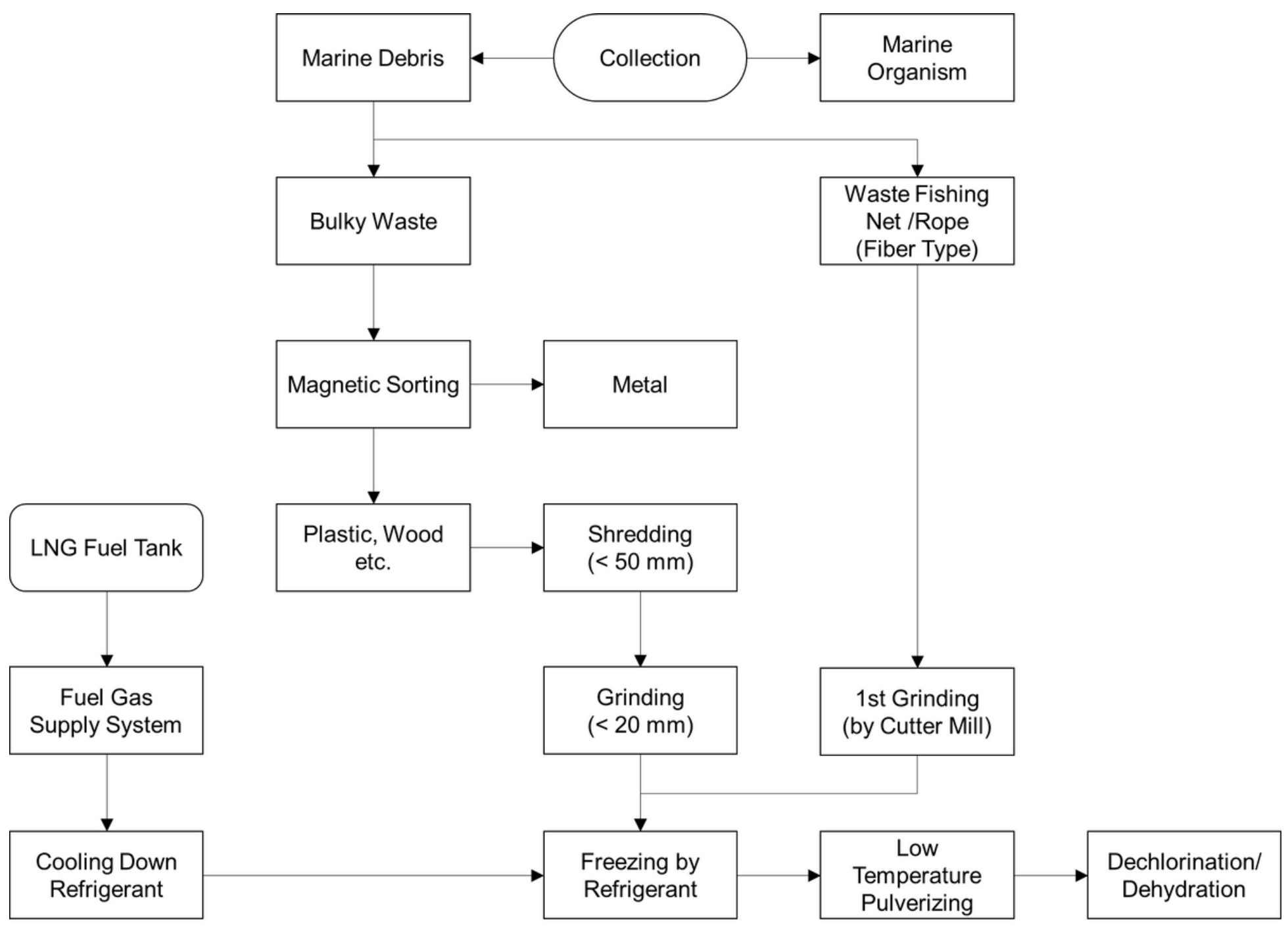

\section{Figure 6}

Low-temperature MD pulverizing process utilizing LCE. 


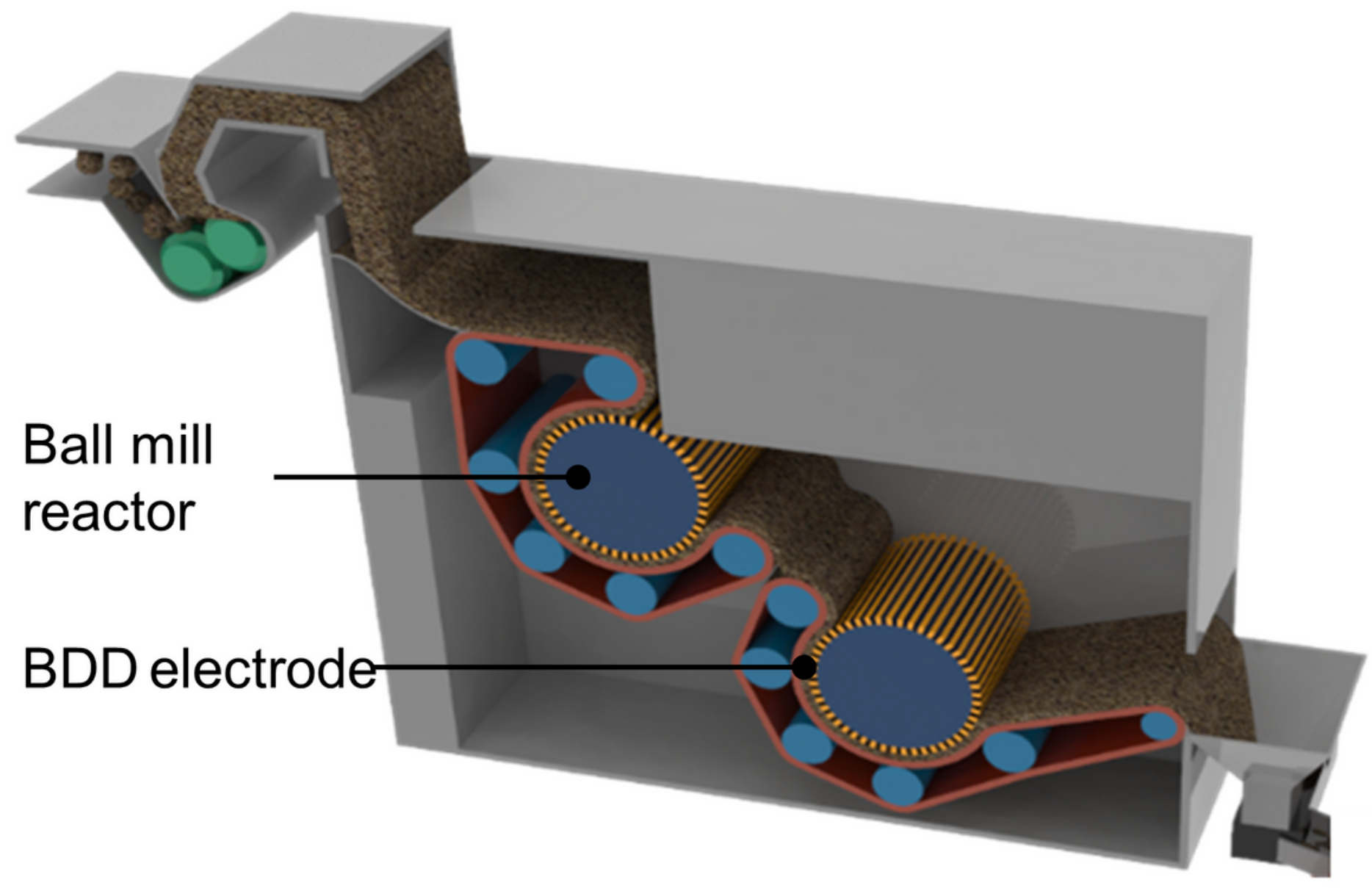

Figure 7

Schematic of the CD equipment. It uses a BDD electrode instead of a IrO2 electrode.

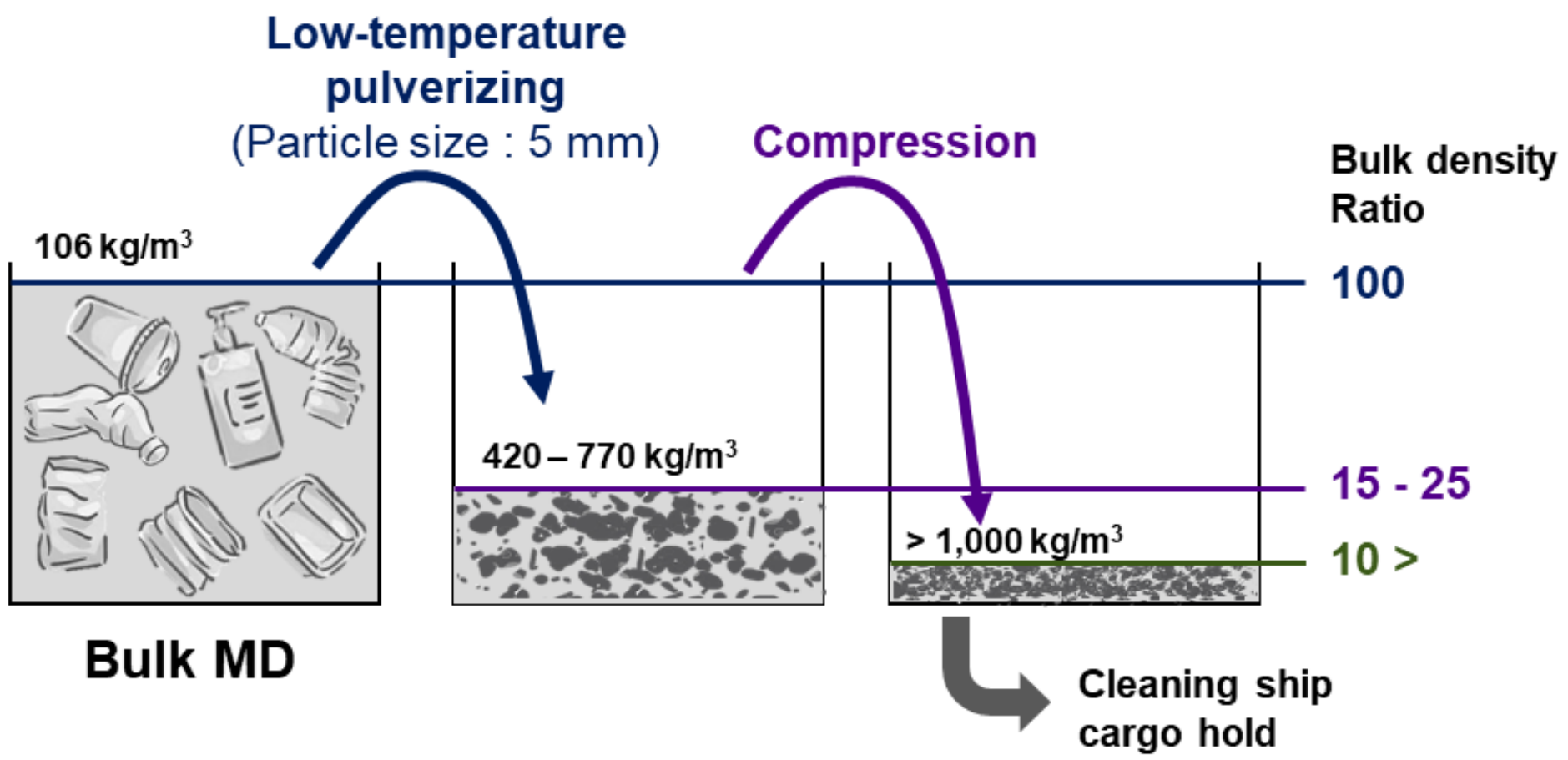

Figure 8 
Storage efficiency according to the stages of MD treatment. Bulk MD contains seawater and has poor storage efficiency due to its low bulk density. Even if only the pulverizing process is carried out, it is possible to achieve a storage efficiency of more than five times and is expected to store more than 10 times through compression 69.

\section{Figure 9}

(a) Map of South Korea (left) and a satellite image (right) of the area near the Busan port in Busan, South Korea, where the MPD was collected. (b) Photograph of the piled MPD left in a storage house without going through and separating the collected waste. The MPD was collected near the Busan Port as of February 12th, 2020. Mainly comprises household plastics, fishing gear, and buoys. (c) The seabed waste near the coast mainly in the form of fibers such as fishing nets or rope.

\section{Figure 10}

Photograph of classified wastes such as (a) plastic bottles, (b) buoys, (c) rope, and (d) fishing nets for LTP tests.

\section{Figure 11}

(a) Relationship between sieve opening size and particle size. Typically, MPD is not in a cube or spherical shape after grinding, so it is filtered up to particles equal to $\sqrt{2}$ times the sieve opening size. (b) Sieve test results. More than half of the PET-CT passed through the $1 \mathrm{~mm}$ sieve. (c) Photo of pulverized particles. In the case of PET-RT, the melted edges were observed, and the pulverized particles were coarser than PETLT (Left). In the case of EPS-RT, pulverization was performed in foam cell units (Right). 